Review

Article

\title{
Current Advancement in Multidisciplinary Treatment for Resectable cStage II/III Esophageal Squamous Cell Carcinoma in Japan
}

\author{
Satoru Matsuda, MD, PhD, ${ }^{1}$ Hiroya Takeuchi, MD, PhD, ${ }^{1}$ Hirofumi Kawakubo, MD, PhD, ${ }^{1}$ \\ Nobutoshi Ando, $\mathrm{MD}, \mathrm{PhD},{ }^{2}$ and Yuko Kitagawa, $\mathrm{MD}, \mathrm{PhD}^{1}$
}

\begin{abstract}
Multidisciplinary treatment comprising surgery, chemotherapy, and radiotherapy for resectable esophageal squamous cell carcinoma (ESCC) is widely used with improved prognosis. Transthoracic esophagectomy (TTE) with extended lymph node (LN) dissection, known as three field LN dissection, has been recommended for ESCC using open thoracotomy or the thoracoscopic approach. The Japan Clinical Oncology Group (JCOG) trial (JCOG1409) is investigating the patients' long term survival using the thoracoscopic approach that has been shown to reduce the incidence of postoperative respiratory complication. For perioperative treatment, neoadjuvant chemotherapy using cisplatin plus 5-fluorouracil (5-FU), has been accepted as the standard of care in Japan based on the JCOG9907 trial. In Western countries, neoadjuvant chemoradiotherapy was shown to prolong overall survival for esophageal cancer, including ESCC. Although surgery has been recognized as an initial curative treatment for esophageal cancer, definitive chemoradiotherapy is an alternative treatment for patients who are unable to undergo thoracotomy or who decline to undergo surgery. This article reviews multidisciplinary treatment advances for ESCC. However, current standard treatments are country dependent and the ongoing trial may help standardize ESCC treatment across various societies.
\end{abstract}

Keywords: esophageal cancer, esophagectomy, multidisciplinary treatment

\section{Introduction}

Esophageal cancer has high metastatic potential and a worse prognosis. Due to its abundant lymphatic flow, lymph node (LN) metastasis could occur in early stages of cancer. In patients with resectable cStage II/III esophageal cancer, surgery is the standard of care. However, postoperative recurrence has been observed in more than half of all

${ }^{1}$ Department of Surgery, Keio University School of Medicine, Tokyo, Japan

${ }^{2}$ International Goodwill Hospital, Yokohama, Kanagawa, Japan

Received: May 1, 2016; Accepted: May 30, 2016

Corresponding author: Hiroya Takeuchi, MD, PhD. Department of Surgery, Keio University School of Medicine, 35 Shinanomachi, Shinjuku-ku, Tokyo 160-8582, Japan

Email: htakeuchi@a6.keio.jp

(C)2016 The Editorial Committee of Annals of Thoracic and Cardiovascular Surgery. All rights reserved. patients who underwent transthoracic esophagectomy (TTE), and prognosis has not been satisfactory. ${ }^{1,2)}$ Chemotherapy and radiotherapy in addition to surgery has been shown to be effective in esophageal cancer. Currently, a multidisciplinary treatment comprising of surgery, chemotherapy, and radiotherapy is widely used with improvement in prognosis. Multidisciplinary treatment is used in many countries but the combinations of modalities are country dependent. This review describes multidisciplinary treatments for resectable cStage II/III esophageal squamous cell carcinoma (ESCC) in Japan, and reviews previous comparative trials for ESCC.

\section{Surgical Procedure}

Esophageal cancer has abundant lymphatic flow and can lead to metastasis even in the early stages. As the lymphatic flow is multidirectional, LN metastasis is widespread and 
random. In particular, LN metastasis of mid-thoracic esophageal cancer has been observed in the cervical to abdominal LNs. ${ }^{3)}$ In order to control the LN metastasis, extended LN dissection has been recommended where mediastinal LNs with bilateral recurrent nerve LNs, and abdominal LNs including LNs around the gastric cardia and LNs along the lesser curvature of the stomach and left gastric artery are routinely dissected. ${ }^{4)}$ In patients with primary tumors between the upper- and mid-thoracic esophagus, three field LN dissection (FD) was carried out in which supraclavicular LNs were dissected simultaneously. Akiyama et al. showed that patients who underwent TTE with 3 FD had significant improvement in overall survival compared to patients who underwent TTE with 2 FD. . $^{5}$ Furthermore, based on the efficacy index which was calculated using the metastatic rate and 5-year survival rate of patients who had metastasis, the 3 FD was shown to be effective for ESCC of the mid-thoracic esophagus. ${ }^{6}$ )

TTE can be performed by open thoracotomy or the thoracoscopic approach. Open thoracotomy has been the globally used classical standard procedure. In contrast, the thoracoscopic approach was first used in 1992 by Cushieri ${ }^{7)}$ and has been gaining widespread utility this past decade. In the thoracoscopic approach, a smaller wound is associated with a lesser degree of postoperative pain and based on a randomized controlled trial from the Netherlands, the incidence of postoperative respiratory complications were significantly reduced in patients who underwent thoracoscopic esophagectomy. ${ }^{8)}$ However, operation durations were longer and several groups reported that postoperative complications requiring reoperation may be increased after thoracoscopic esophagectomy. ${ }^{9-11)}$ The currently ongoing Japan Clinical Oncology Group (JCOG) 1409 trial was initiated to clarify the non-inferiority of thoracoscopic esophagectomy against open thoracotomy ${ }^{12}$ ) by investigating the long term survival rate of patients undergoing thoracoscopic esophagectomy.

\section{Adjuvant Chemotherapy}

In general, adjuvant chemotherapy may help eliminate residual cancer cell and micro metastasis. Because chemotherapy is preceded by surgery, patients with a high risk of cancer recurrence can be selected for therapy based on pathological findings of the surgical specimen. However, clinical response to this therapy cannot be evaluated as there is no observable lesion after curative surgery. Furthermore, a decreased dose intensity of chemotherapy might be required for postoperative morbid patients. ${ }^{13)}$
In Japan, the JCOG conducted sequential clinical trials to improve the survival for patients with ESCC (Table 1). ${ }^{2,12,14-24)}$ The survival benefit of adjuvant chemotherapy in cStage II/III ESCC was investigated in the JCOG8503 study, where adjuvant radiotherapy (50 Gy) was compared with adjuvant chemotherapy consisting of cisplatin (CDDP) and vindesin (VDS). ${ }^{15}$ ) The five year overall survival rate was $44 \%$ in the adjuvant radiotherapy group and $42 \%$ in the adjuvant chemotherapy group, indicating no difference in overall survival. At this time, because TTE with 3 FD was accepted as an effective surgical procedure in Japan, survival benefit of adjuvant chemotherapy was compared with TTE alone. Consequently in the JCOG8806 study, adjuvant chemotherapy using CDDP and VDS combination was compared with surgery alone. The 5 year overall survival rate was $45 \%$ in the surgery group and $48 \%$ in the adjuvant chemotherapy group, and no survival benefit was achieved. ${ }^{16)}$

In the 90's, adjuvant chemotherapy of 5-fluorouracil (5-FU) and CDDP (CF) was compared with surgery alone in the JCOG9204 study. ${ }^{18)}$ Consequently, the 5-year disease free survival was significantly extended in the CF chemotherapy group (55\%) compared to the surgery alone group (45\%). In subgroup analysis, the survival benefit of adjuvant chemotherapy was remarkable in patients with positive LN metastasis. Therefore, adjuvant chemotherapy using CF could be a treatment option in Japan for patients with advanced esophageal cancer without neoadjuvant treatment and with positive LN metastasis after surgery.

In western society, Pouliquen reported a randomized control trial comparing adjuvant chemotherapy using $\mathrm{CF}$ with surgery alone. ${ }^{25)}$ In that study, no significant difference in survival was noted. Of interest, a meta-analysis conducted by Zhang concluded that indication of adjuvant treatment for ESCC might be determined according to pathological stage. ${ }^{26)}$

\section{Neoadjuvant Chemotherapy}

In general, there are several benefits of neoadjuvant treatment. First, neoadjuvant treatment can be delivered before surgery, leading to a high completion rate. Second, volume reduction of the primary tumor could lead to higher $\mathrm{R} 0$ rate, and control of micro metastasis might lead favorable prognosis. Third, response to chemotherapy can be evaluated based on the resected specimen, which may aid in selection of the postoperative treatment regimen. For non-responders however, tumor progression might result in a non-curative resection. Despite the benefits, it 


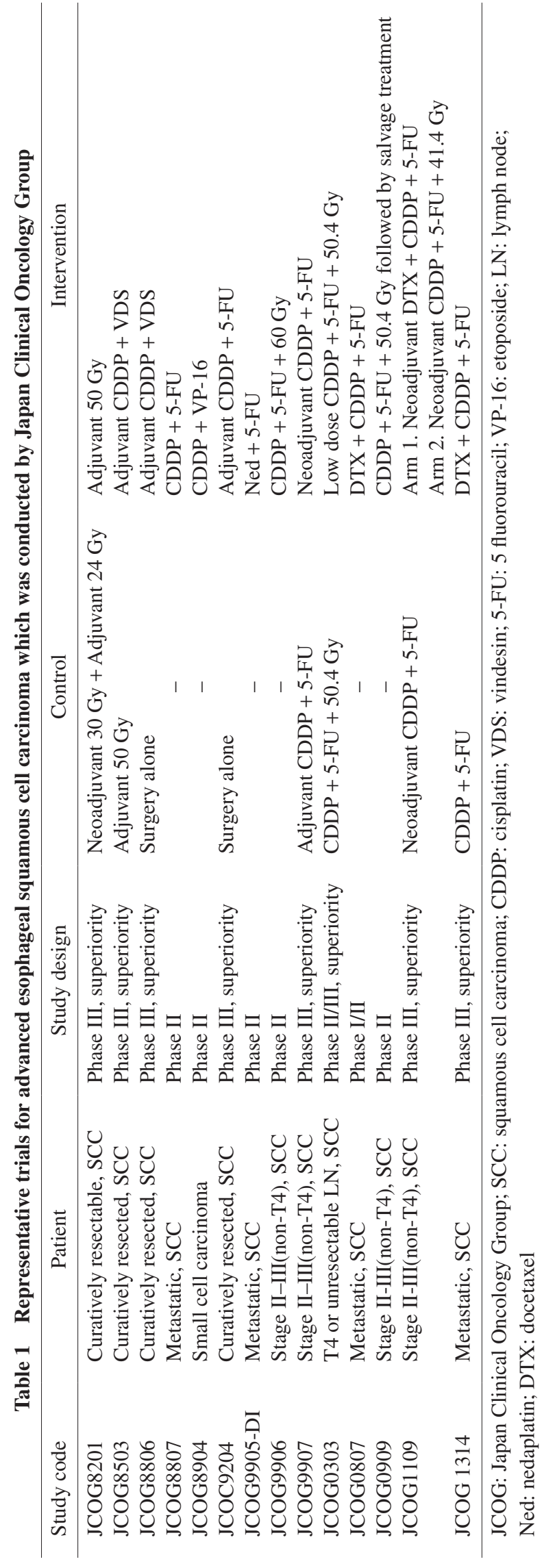

should be also noted that adverse events of neoadjuvant treatment might induce postoperative complications.

The JCOG9907 study in Japan compared the survival benefit of $\mathrm{CF}$ as a neoadjuvant chemotherapy (NAC) with $\mathrm{CF}$ as an adjuvant chemotherapy for patients with resectable cStage II/III ESCC. ${ }^{2)}$ In this study, the overall survival was significantly prolonged in the NAC group $(\mathrm{p}=$ $0.01)$ at the second interim analysis and patients' accrual was stopped. Updated analyses showed that 5-year overall survival rate was $43 \%$ in adjuvant chemotherapy group and $55 \%$ in NAC group $(\mathrm{p}=0.04)$. In terms of the postoperative complications, there was no remarkable difference in postoperative complications between the two groups. The mortality rate was less than $1 \%$, with one patient in each group dying from surgery-related causes. Based on these results, NAC with CF followed by TTE with extended $\mathrm{LN}$ dissection has been the current standard treatment for patients with ESCC in Japan.

Table 2 2,27-36) shows nine RCTs in which ESCC patients were included and the efficacy of NAC investigated that were reviewed. Besides the JCOG9907 trial, eight RCTs in which ESCC was included were reported, including seven from Western countries and one from Asia. Seven of these eight RCTs showed that there was no significant difference in overall survival between NAC followed by TTE and TTE alone. Sjoquist conducted a meta-analysis, using ten RCTs (Randomized control trial) for ESCC and esophageal adenocarcinoma to investigate the survival benefit of NAC. ${ }^{37)}$ In the study, the pooled hazard ratio (HR) was $0.87(0.79-0.96, p=0.005)$ and indicated a survival benefit of NAC. However, a subgroup analysis by histological type for those studies where histology was available gave an HR of $0.91(0.81-1.04, \mathrm{p}=0.18)$ for ESCC.

In the subgroup analysis of the JCOG9907 trial, there was no significant difference in overall survival between NAC and surgery alone in patients with cStage III. ${ }^{2)}$ Furthermore, in western countries, neoadjuvant chemoradiotherapy (NACRT) that shows higher efficacy in local control has been used as a standard treatment. Recently, Hara et al. reported a high response rate from triplet chemotherapy using CDDP, 5-FU, and docetaxel (DCF) and this could be another treatment option. ${ }^{38)}$ In the phase II trial, treatment completion rate was $90.5 \%$ and clinical response rate was $64.3 \%$ and pathological complete response was observed in $17 \%$. For adverse events, neutropenia ( $\geq$ Grade 3 ) was observed in $83 \%$ of patients but there were no cases of treatment related deaths.

From the current results, a three-arm phase III trial, JCOG1109 trial, was started in Japan to confirm the 


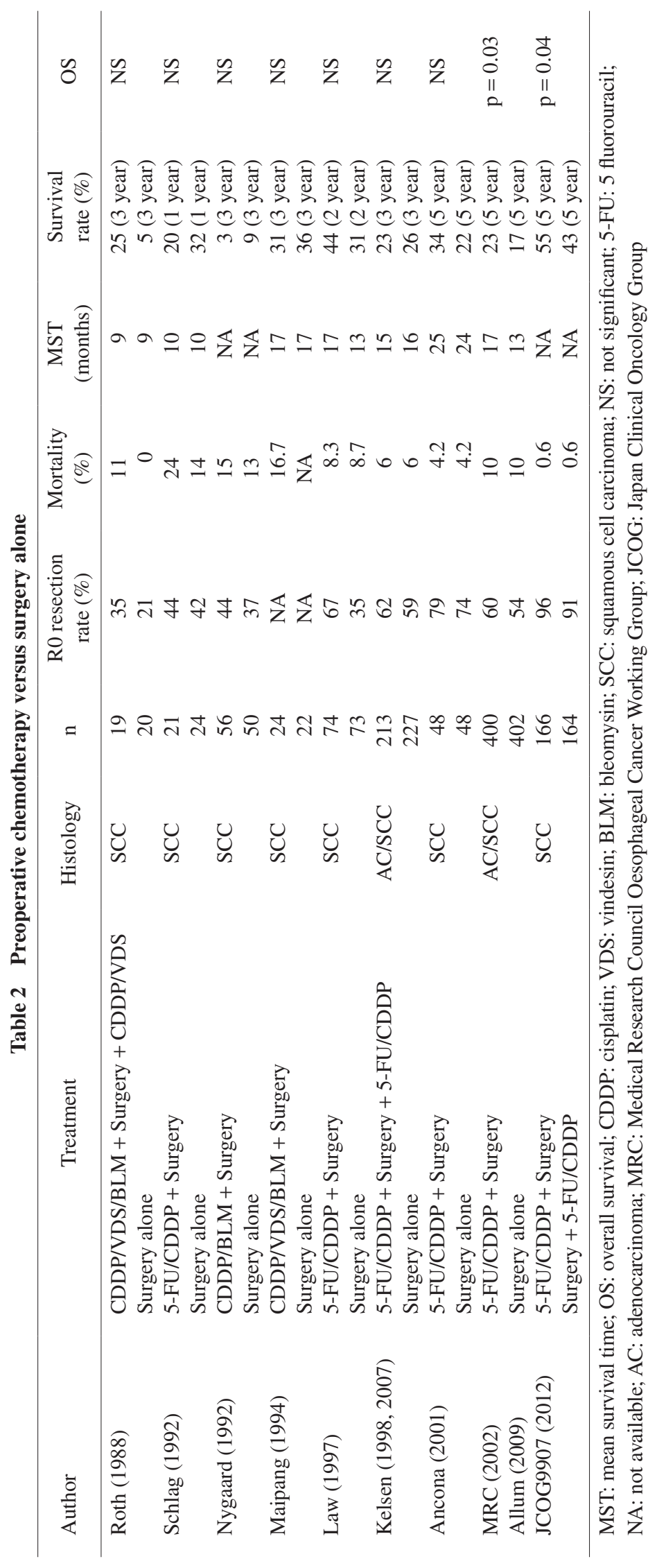




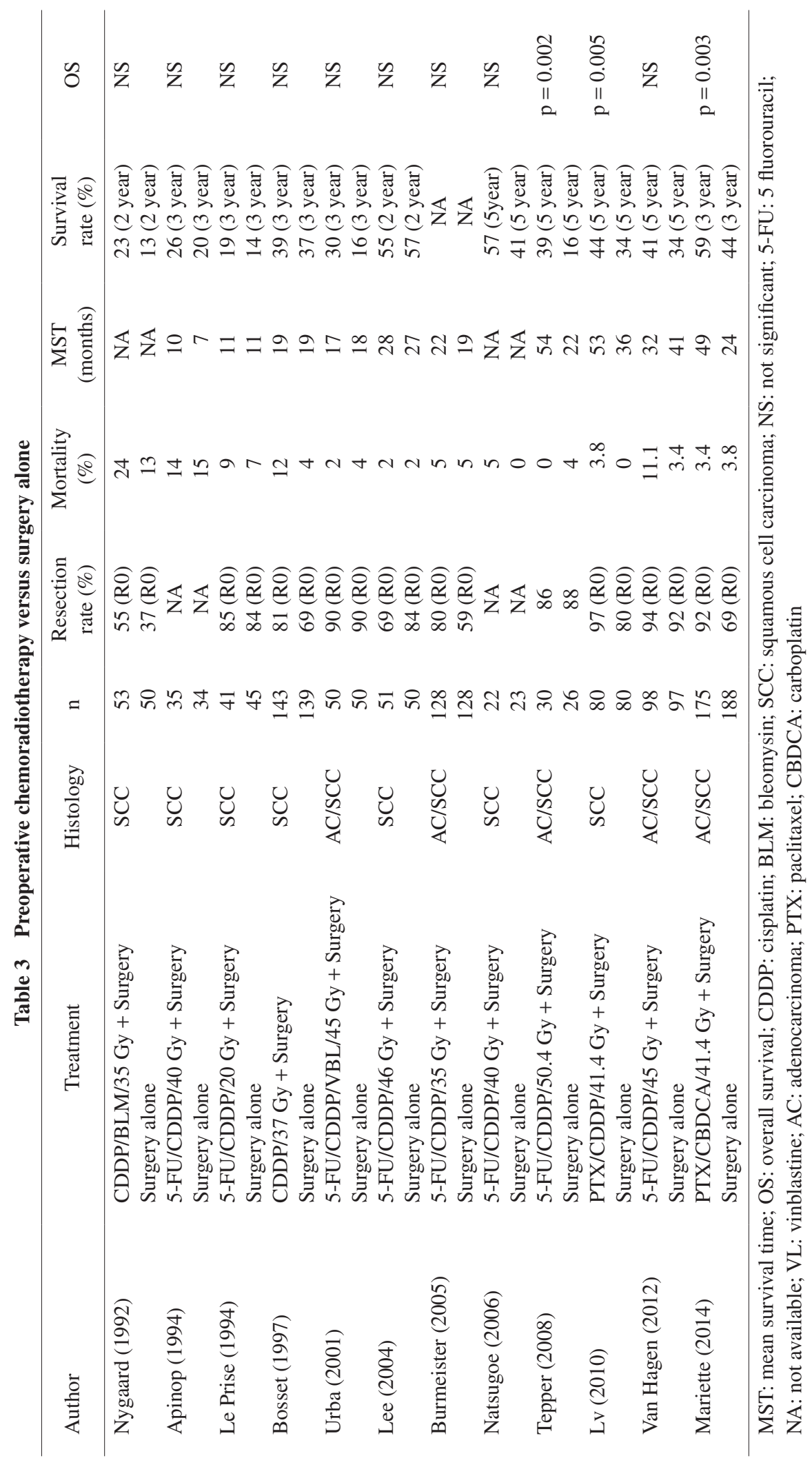


superiority of DCF over $\mathrm{CF}$ and the superiority of chemoradiotherapy with $\mathrm{CF}$ over $\mathrm{CF}$ as preoperative therapy for ESCC. ${ }^{23)}$

\section{Neoadjuvant Chemoradiotherapy}

In NACRT, concurrent chemotherapy combined with radiotherapy less than $50 \mathrm{~Gy}$ is administered and curative surgery is planned after neoadjuvant treatment regardless of the response. ${ }^{14)}$

Table $3^{1,29,39-48)}$ shows 12 RCTs in which patients with ESCC were included and efficacy of NACRT was investigated were reviewed. Despite differences in total radiotherapy dose and regimen of concurrent chemotherapy, most of the studies show an increase in the $\mathrm{R} 0$ resection rate in the NACRT group. Three of 12 trials showed significant overall survival benefit in the NACRT group. Van Hagen et al. investigated the superiority of NACRT using paclitaxel plus carboplatin with radiation of 41.4 Gy over surgery alone. ${ }^{1)}$ Consequently, the median survival time was 24 months in the group with surgery alone against 49.4 months in the NACRT group, showing that NACRT significantly prolonged overall survival. ${ }^{1)}$ The operative mortality rate was $3 \%$ in both groups in this trial. Shapiro et al. reported maintenance of the survival benefit in this trial in 2015.49) Sjoquist et al. conducted a meta-analysis of NACRT versus surgery alone and showed that the pooled HR for all-cause mortality for neoadjuvant chemoradiotherapy was $0.78(0.70-0.88$, $\mathrm{p}<0.0001$ ), and the survival benefit was similar in both ESCC (HR 0.80, 0.68-0.93, p = 0.004) and adenocarcinoma (HR 0.75, 0.59-0.95, $\mathrm{p}=0.02)^{37}$ )

To date, there has been no RCT comparing NAC and NACRT in patients with ESCC. The JCOG1109 trial could encourage establishment of a standardized multidisciplinary treatment for ESCC. ${ }^{23)}$

\section{Definitive Chemoradiotherapy}

Although surgery has been recognized as an initial curative treatment for esophageal cancer, the TTE is invasive and the mortality and morbidity remains high. In patients who are unable to undergo thoracotomy or who decline to undergo surgery, definitive chemoradiotherapy (dCRT) can be an alternative to esophagectomy. One of the curative treatment options is dCRT in which a total radiation dose of $>50$ Gy is combined with concurrent chemotherapy.

There were three previous randomized phase III trials which compared esophagectomy with dCRT. In the FFCD9102 study, all patients received chemoradiotherapy and patients who responded to the treatment with no contraindication were randomly assigned to surgery or continuation of chemoradiotherapy. ${ }^{50)}$ Consequently, there was no significant difference in the 2 year survival rate (Surgery group, 34\%; Chemoradiotherapy group, 40\%) and the 3-month mortality was $9.3 \%$ in the surgery group. Similar to the FFCD9102 study, the other two RCTs reported no significant difference in survival as well..$^{51,52)}$

To date, there are nine observational studies comparing dCRT with surgery. ${ }^{53-61)}$ Of them, five reports were submitted from Japan and in two out of nine studies, surgery was shown to significantly extend the overall survival. Consequently, dCRT has been used as an alternative to surgery in patients unable to undergo surgical treatment.

When dCRT was selected as the initial treatment with a total radiation dose of $>50 \mathrm{~Gy}$, salvage esophagectomy, particularly TTE, could be a treatment option. In the ongoing JCOG0909 trial for patients who refuse to undergo TTE, dCRT is conducted as the initial treatment, and salvage treatments, including TTE or endoscopic submucosal resection for residual disease or early local recurrence, are planned. In this trial, on the basis of the previous studies, ${ }^{62,63)}$ the radiation protocol was set at 50.4 Gy in 28 fractions using the CT simulator with a three- or four-field technique to reduce the late radiation toxicities. Because clinical target volume was modified depending on the tumor location, the radiation field in the JCOG0909 trial was smaller than in the JCOG9906 trial.

As a future perspective, the aforementioned treatment strategy might be an ideal treatment option for patients with cStage II/III ESCC.

\section{Conclusions}

Although the advancement of multidisciplinary treatment has improved survival in patients with ESCC, the recurrence rate has been still high, particularly in locally advanced cases. Furthermore, one of the challenging issues is that there are various combinations of treatments in the world, resulting in that the current standard treatment is country dependent. As a future perspective, the ongoing Japanese trial could indicate whether the more intense neoadjuvant treatment would extend the postoperative survival in patients with resectable ESCC, particularly for clinical stage III. In patients with surgically unresectable ESCC, triplet chemotherapy and chemoradiotherapy may increase the response rate, which will enable more patients to undergo curative surgery. Recently, the effectiveness of new therapeutic agents, which include 
immune check point inhibitors, has been reported. ${ }^{64)}$ Further improvement with multidisciplinary treatment for ESCC encourages the establishment of a standardized treatment for ESCC across various countries.

\section{Disclosure Statement}

Yuko Kitagawa received a research grant from Yakult Honsha Co., Ltd. Other authors have no conflict of interest to disclose.

\section{References}

1) van Hagen P, Hulshof MC, van Lanschot JJ, et al. Preoperative chemoradiotherapy for esophageal or junctional cancer. N Eng J Med 2012; 366: 2074-84.

2) Ando $\mathrm{N}$, Kato $\mathrm{H}$, Igaki $\mathrm{H}$, et al. A randomized trial comparing postoperative adjuvant chemotherapy with cisplatin and 5-fluorouracil versus preoperative chemotherapy for localized advanced squamous cell carcinoma of the thoracic esophagus (JCOG9907). Ann Surg Oncol 2012; 19: 68-74.

3) Takeuchi H, Fujii H, Ando N, et al. Validation study of radio-guided sentinel lymph node navigation in esophageal cancer. Ann Surg 2009; 249: 757-63.

4) Ando N, Ozawa S, Kitagawa Y, et al. Improvement in the results of surgical treatment of advanced squamous esophageal carcinoma during 15 consecutive years. Ann Surg 2000; 232: 225-32.

5) Akiyama H, Tsurumaru M, Udagawa $H$, et al. Radical lymph node dissection for cancer of the thoracic esophagus. Ann Surg 1994; 220: 364-72; discussion 372-3.

6) Udagawa H, Ueno M, Shinohara H, et al. The importance of grouping of lymph node stations and rationale of three-field lymphoadenectomy for thoracic esophageal cancer. J Surg Oncol 2012; 106: 742-7.

7) Cuschieri A, Shimi S, Banting S. Endoscopic oesophagectomy through a right thoracoscopic approach. J R Coll Surg Edinb 1992; 37: 7-11.

8) Biere SS, van Berge Henegouwen MI, Maas KW, et al. Minimally invasive versus open oesophagectomy for patients with oesophageal cancer: a multicentre, open-label, randomised controlled trial. Lancet 2012; 379: 1887-92.

9) Nozaki I, Kato K, Igaki H, et al. Evaluation of safety profile of thoracoscopic esophagectomy for T1bNOM0 cancer using data from JCOG0502: a prospective multicenter study. Surg Endosc 2015; 29: 3519-26.

10) Takeuchi H, Miyata H, Gotoh M, et al. A risk model for esophagectomy using data of 5354 patients included in a Japanese nationwide web-based database. Ann Surg 2014; 260: 259-66.

11) Mamidanna R, Bottle A, Aylin P, et al. Short-term outcomes following open versus minimally invasive esophagectomy for cancer in England: a populationbased national study. Ann Surg 2012; 255: 197-203.
12) Kataoka K, Takeuchi H, Mizusawa J, et al. A randomized Phase III trial of thoracoscopic versus open esophagectomy for thoracic esophageal cancer: Japan Clinical Oncology Group Study JCOG1409. Jpn J Clin Oncol 2016; 46: 174-7.

13) Ando N, Neoadjuvant and Adjuvant Therapy. In: Ando $N$ ed.; Esophageal Squamous Cell Carcinoma. New York: Springer, 2015; pp 177-96.

14) Iizuka $T$, Ide $H$, Kakegawa $T$, et al. Preoperative radioactive therapy for esophageal carcinoma: randomized evaluation trial in eight institutions. Chest 1988; 93: 1054-8.

15) Japanese Esophageal Oncology Group. A comparison of chemotherapy and radiotherapy as adjuvant treatment to surgery for esophageal carcinoma. Chest 1993; 104: 203-7.

16) Ando N, lizuka T, Kakegawa T, et al. A randomized trial of surgery with and without chemotherapy for localized squamous carcinoma of the thoracic esophagus: the Japan Clinical Oncology Group Study. J Thorac Cardiovas Surg 1997; 114: 205-9.

17) Iizuka $T$, Kakegawa $T$, Ide $H$, et al. Phase II evaluation of cisplatin and 5-fluorouracil in advanced squamous cell carcinoma of the esophagus: a Japanese Esophageal Oncology Group Trial. Jpn J Clin Oncol 1992; 22: $172-6$.

18) Ando N, Iizuka T, Ide H, et al. Surgery plus chemotherapy compared with surgery alone for localized squamous cell carcinoma of the thoracic esophagus: a Japan Clinical Oncology Group Study_JCOG9204. J Clin Oncol 2003; 21: 4592-6.

19) Kato K, Muro K, Ando N, et al. A phase II study of nedaplatin and 5-fluorouracil in metastatic squamous cell carcinoma of the esophagus: The Japan Clinical Oncology Group (JCOG) Trial (JCOG 9905-DI). Esophagus 2014; 11: 183-8.

20) Kato K, Muro K, Minashi K, et al. Phase II study of chemoradiotherapy with 5-fluorouracil and cisplatin for Stage II-III esophageal squamous cell carcinoma: JCOG trial (JCOG 9906). Int J Rad Oncol Bio Phys 2011; 81: 684-90.

21) Shinoda M, Ando N, Kato K, et al. Randomized study of low-dose versus standard-dose chemoradiotherapy for unresectable esophageal squamous cell carcinoma (JCOG0303). Cancer Sci 2015; 106: 407-12.

22) Hironaka $S$, Tsubosa Y, Mizusawa J, et al. Phase I/II trial of 2-weekly docetaxel combined with cisplatin plus fluorouracil in metastatic esophageal cancer (JCOG0807). Cancer Sci 2014; 105: 1189-95.

23) Nakamura K, Kato K, Igaki H, et al. Three-arm phase III trial comparing cisplatin plus 5-FU (CF) versus docetaxel, cisplatin plus 5-FU (DCF) versus radiotherapy with $\mathrm{CF}$ (CF-RT) as preoperative therapy for locally advanced esophageal cancer (JCOG1109, NExT study). Jpn J Clin Oncol 2013; 43: 752-5.

24) Kataoka K, Tsushima T, Mizusawa J, et al. A randomized controlled Phase III trial comparing 2-weekly 
docetaxel combined with cisplatin plus fluorouracil (2-weekly DCF) with cisplatin plus fluorouracil (CF) in patients with metastatic or recurrent esophageal cancer: rationale, design and methods of Japan Clinical Oncology Group study JCOG1314 (MIRACLE study). Jpn J Clin Oncol 2015; 45: 494-8.

25) Pouliquen X, Levard H, Hay JM, et al. 5-Fluorouracil and cisplatin therapy after palliative surgical resection of squamous cell carcinoma of the esophagus. A multicenter randomized trial. French Associations for Surgical Research. Ann Surg 1996; 223: 127-33.

26) Zhang SS, Yang H, Xie X, et al. Adjuvant chemotherapy versus surgery alone for esophageal squamous cell carcinoma: a meta-analysis of randomized controlled trials and nonrandomized studies. Dis Esophagus 2014; 27: $574-84$.

27) Roth JA, Pass HI, Flanagan MM, et al. Randomized clinical trial of preoperative and postoperative adjuvant chemotherapy with cisplatin, vindesine, and bleomycin for carcinoma of the esophagus. J Thorac Cardiovas Surg 1988; 96: 242-8.

28) Schlag PM. Randomized trial of preoperative chemotherapy for squamous cell cancer of the esophagus. Arch Surg 1992; 127: 1446-50.

29) Nygaard K, Hagen S, Hansen HS, et al. Pre-operative radiotherapy prolongs survival in operable esophageal carcinoma: a randomized, multicenter study of pre-operative radiotherapy and chemotherapy. World J Surg 1992; 16: 1104-9.

30) Maipang T, Vasinanukorn P, Petpichetchian C, et al. Induction chemotherapy in the treatment of patients with carcinoma of the esophagus. J Surg Oncol 1994; 56: 191-7.

31) Law S, Fok M, Chow S, et al. Preoperative chemotherapy versus surgical therapy alone for squamous cell carcinoma of the esophagus: a prospective randomized trial. J Thorac Cardiovas Surg 1997; 114: 210-7.

32) Kelsen DP, Ginsberg R, Pajak TF, et al. Chemotherapy followed by surgery compared with surgery alone for localized esophageal cancer. N Eng J Med 1998; 339: 1979-84.

33) Kelsen DP, Winter KA, Gunderson LL, et al. Long-term results of RTOG trial 8911 (USA Intergroup 113): a random assignment trial comparison of chemotherapy followed by surgery compared with surgery alone for esophageal cancer. J Clin Oncol 2007; 25: 3719-25.

34) Ancona E, Ruol A, Santi S, et al. Only pathologic complete response to neoadjuvant chemotherapy improves significantly the long term survival of patients with resectable esophageal squamous cell carcinoma: final report of a randomized, controlled trial of preoperative chemotherapy versus surgery alone. Cancer 2001; 91: 2165-74.

35) Medical Research Council Oesophageal Cancer Worling Group. Surgical resection with or without preoperative chemotherapy in oesophageal cancer: a randomised controlled trial. Lancet 2002; 359: 1727-33.
36) Allum WH, Stenning SP, Bancewicz J, et al. Long-term results of a randomized trial of surgery with or without preoperative chemotherapy in esophageal cancer. J Clin Oncol 2009; 27: 5062-7.

37) Sjoquist KM, Burmeister BH, Smithers BM, et al. Survival after neoadjuvant chemotherapy or chemoradiotherapy for resectable oesophageal carcinoma: an updated meta-analysis. Lancet Oncol 2011; 12: 681-92.

38) Hara H, Tahara M, Daiko H, et al. Phase II feasibility study of preoperative chemotherapy with docetaxel, cisplatin, and fluorouracil for esophageal squamous cell carcinoma. Cancer Sci 2013; 104: 1455-60.

39) Apinop C, Puttisak P, Preecha N. A prospective study of combined therapy in esophageal cancer. Gastroenterol Hepatol 1994; 41: 391-3.

40) Le Prise E, Etienne PL, Meunier B, et al. A randomized study of chemotherapy, radiation therapy, and surgery versus surgery for localized squamous cell carcinoma of the esophagus. Cancer 1994; 73: 1779-84.

41) Bosset JF, Gignoux M, Triboulet JP, et al. Chemoradiotherapy followed by surgery compared with surgery alone in squamous-cell cancer of the esophagus. N Eng J Med 1997; 337: 161-7.

42) Urba SG, Orringer MB, Turrisi A, et al. Randomized trial of preoperative chemoradiation versus surgery alone in patients with locoregional esophageal carcinoma. J Clin Oncol 2001; 19: 305-13.

43) Lee JL, Park SI, Kim SB, et al. A single institutional phase III trial of preoperative chemotherapy with hyperfractionation radiotherapy plus surgery versus surgery alone for resectable esophageal squamous cell carcinoma. Ann Oncol 2004; 15: 947-54.

44) Burmeister BH, Smithers BM, Gebski V, et al. Surgery alone versus chemoradiotherapy followed by surgery for resectable cancer of the oesophagus: a randomised controlled phase III trial. Lancet Oncol 2005; 6: 659-68.

45) Natsugoe S, Okumura H, Matsumoto M, et al. Randomized controlled study on preoperative chemoradiotherapy followed by surgery versus surgery alone for esophageal squamous cell cancer in a single institution. Dis Esophagus 2006; 19: 468-72.

46) Tepper J, Krasna MJ, Niedzwiecki D, et al. Phase III trial of trimodality therapy with cisplatin, fluorouracil, radiotherapy, and surgery compared with surgery alone for esophageal cancer: CALGB 9781. J Clin Oncol 2008; 26: 1086-92.

47) Lv J, Cao XF, Zhu B, et al. Long-term efficacy of perioperative chemoradiotherapy on esophageal squamous cell carcinoma. World J Gastroenterol 2010; 16: 1649-54.

48) Mariette C, Dahan L, Mornex F, et al. Surgery alone versus chemoradiotherapy followed by surgery for stage I and II esophageal cancer: final analysis of randomized controlled phase III trial FFCD 9901. J Clin Oncol 2014; 32: 2416-22. 
49) Shapiro J, van Lanschot JJ, Hulshof MC, et al. Neoadjuvant chemoradiotherapy plus surgery versus surgery alone for oesophageal or junctional cancer (CROSS): long-term results of a randomised controlled trial. Lancet Oncol 2015; 16: 1090-8.

50) Bedenne L, Michel P, Bouche O, et al. Chemoradiation followed by surgery compared with chemoradiation alone in squamous cancer of the esophagus: FFCD 9102. J Clin Oncol 2007; 25: 1160-8.

51) Stahl M, Stuschke M, Lehmann N, et al. Chemoradiation with and without surgery in patients with locally advanced squamous cell carcinoma of the esophagus. J Clin Oncol 2005; 23: 2310-7.

52) Teoh AY, Chiu PW, Yeung WK, et al. Long-term survival outcomes after definitive chemoradiation versus surgery in patients with resectable squamous carcinoma of the esophagus: results from a randomized controlled trial. Ann Oncol 2013; 24: 165-71.

53) Chan R, Morrill S, Freeman D, et al. Bi-modality (chemo-radiation) versus tri-modality (chemo-radiation followed by surgery) treatment for carcinoma of the esophagus. Dis Esophagus 2001; 14: 202-7.

54) Hironaka S, Ohtsu A, Boku N, et al. Nonrandomized comparison between definitive chemoradiotherapy and radical surgery in patients with $\mathrm{T}(2-3) \mathrm{N}$ (any) $\mathrm{M}(0)$ squamous cell carcinoma of the esophagus. Int $\mathbf{J}$ Rad Oncol Bio Phys 2003; 57: 425-33.

55) Nagata M, Yamamoto H, Takiguchi N, et al. Neoadjuvant chemoradiotherapy followed by esophagectomy versus definitive chemoradiotherapy in resectable stage II/III (T1-3N0, 1M0) esophageal squamous cell carcinoma. Esophagus 2006; 3: 105-11.

56) Adams R, Morgan M, Mukherjee S, et al. A prospective comparison of multidisciplinary treatment of oesophageal cancer with curative intent in a UK cancer network. Eur J Surg Oncol 2007; 33: 307-13.
57) Hsu FM, Lin CC, Lee JM, et al. Improved local control by surgery and paclitaxel-based chemoradiation for esophageal squamous cell carcinoma: results of a retrospective non-randomized study. J Surg Oncol 2008; 98: 34-41.

58) Yamashita $H$, Nakagawa $K$, Yamada $K$, et al. A single institutional non-randomized retrospective comparison between definitive chemoradiotherapy and radical surgery in 82 Japanese patients with resectable esophageal squamous cell carcinoma. Dis Esophagus 2008; 21: 430-6.

59) Abrams JA, Buono DL, Strauss J, et al. Esophagectomy compared with chemoradiation for early stage esophageal cancer in the elderly. Cancer 2009; 115: 4924-33.

60) Ariga H, Nemoto K, Miyazaki S, et al. Prospective comparison of surgery alone and chemoradiotherapy with selective surgery in resectable squamous cell carcinoma of the esophagus. Int J Rad Oncol Bio Phys 2009; 75: 348-56.

61) Matsuda S, Tsubosa Y, Niihara M, et al. Comparison of transthoracic esophagectomy with definitive chemoradiotherapy as initial treatment for patients with esophageal squamous cell carcinoma who could tolerate transthoracic esophagectomy. Ann Surg Oncol 2015; 22: 1866-73.

62) Kato K, Nakajima TE, Ito $Y$, et al. Phase II study of concurrent chemoradiotherapy at the dose of $50.4 \mathrm{~Gy}$ with elective nodal irradiation for Stage II-III esophageal carcinoma. Jpn J Clin Oncol 2013; 43: 608-15.

63) Minsky BD, Pajak TF, Ginsberg RJ, Pisansky TM, Martenson J, Komaki R, et al. INT 0123 (Radiation Therapy Oncology Group 94-05) phase III trial of combined-modality therapy for esophageal cancer: high-dose versus standard-dose radiation therapy. J Clin Oncol 2002; 20: 1167-74.

64) Lote H, Cafferkey C, Chau I. PD-1 and PD-L1 blockade in gastrointestinal malignancies. Cancer Treat Rev 2015; 41: 893-903. 